
\title{
\& Research Square \\ Risk Factors for Injuries in Female Soldiers: a Systematic Review
}

\section{Ben Schram ( $\nabla$ bschram@bond.edu.au )}

Tactical Research Unit, Bond University

\section{Elisa Canetti}

Tactical Research Unit, Bond University

\section{Rob Orr}

Tactical Research Unit, Bond University

\section{Rodney Pope}

Charles Sturt University

\section{Research Article}

Keywords: tactical, military, women, injury

Posted Date: November 8th, 2021

DOI: https://doi.org/10.21203/rs.3.rs-1037595/v1

License: (9) This work is licensed under a Creative Commons Attribution 4.0 International License. Read Full License

Version of Record: A version of this preprint was published at BMC Sports Science, Medicine and Rehabilitation on March 29th, 2022. See the published version at https://doi.org/10.1186/s13102-02200443-z. 


\section{Abstract}

Background: Female soldiers form an integral part of any modern defence force. Previous reports have highlighted that female soldiers report injuries at higher rates than male personnel. One possible reason for this is an actual difference in underlying injury rates, purported to be due to several factors, including levels of fitness. The aim of this review was to determine risk factors for injuries in female soldiers.

Methods: A systematic search was conducted for studies which reported on risk factors for injuries in female soldiers. Databases searched included PUBMED, CINAHL and Medline through OVID. Eligible studies were rated for their methodological quality using the Critical Appraisal Skills Program (CASP) tools and data were extracted and synthesized using a critical narrative approach.

Results: A total of 18 articles were included in this review which reported on 18 risk factors for injury. Smoking, previous injury, no history of deployment, heavy occupational tasks, lower levels of aerobic fitness and lower number of push-up repetitions appear to be risk factors for injuries in female soldiers. Age, height, body fat, high or low BMI and body mass do not appear to be consistent risk factors for injury in female soldiers and there appears to be minimal evidence for current levels of activity, sit-up ability, and other assessments of strength, power, speed, or movement being associated with injury risk. Additionally, neither flexibility nor previous levels of activity appear to be associated with injury risk in female soldiers.

Conclusion: Strategies to improve aerobic fitness and upper limb endurance, reduce smoking, and optimise rehabilitation from injuries and risk management for heavy occupational tasks need to be developed for female soldiers. Such strategies are also likely to reduce risks for male soldiers.

\section{Background}

With more direct combat roles being made available (1), female soldiers continue to play an integral part in a modern military (2). Ensuring female personnel can perform at an optimal level, free of the burden of injury is therefore imperative to maintaining combat readiness and effectiveness (3). Musculoskeletal injuries are detrimental to operational readiness (4), causing a higher rate of hospitalization than direct combat related injuries in deployed personnel (5-7). Reduction of injuries in military contexts is therefore considered a force multiplier (8).

Female soldiers have been found to suffer injuries at a higher rate, both in training $(9,10)$ and on operations $(11,12)$ when compared to their male colleagues, although this sex-based difference does not hold true across all military contexts and in some contexts male personnel have been observed to have higher injury rates than female personnel $(13,14)$. There is also evidence that female soldiers may sustain injuries to different body sites when compared to male soldiers (15-17) and exhibit some differences in risk factors for injury, due to anthropometric, biomechanical, and anatomical differences. In basic training contexts where male and female recruits train together, despite males experiencing greater external training loads as measured by total distance covered, female soldiers tended to have a greater 
internal training load as measured by heart rate and ratings of perceived exertion and report more muscle soreness and fatigue (18).

Given that, historically, injury reduction programs have been designed primarily around male soldiers, as they comprise the greatest proportion of army personnel, these programs may not be optimally managing risks of injuries in females. Given the reported differences between male and female soldiers, the aim of this review was to identify, analyse, and synthesize findings from studies which have reported on risk factors for injuries in female soldiers, to inform targeted injury reduction programs.

\section{Methods}

This review was registered as part of a broader research project with Prospero (CRD42020170003). To source articles relevant to this review, dedicated search terms were developed after a preliminary rapid search. The databases PubMed, CINAHL, and Medline through OVID were searched systematically using the themes of female, military (and army), and injury, or derivatives thereof. An example of the search terms used can be found in Table 1. 
Table 1

Example of the search terms used in Pubmed

\begin{tabular}{|lll|}
\hline Theme 1 & Theme 2 & Theme 3 \\
\hline female[Title/Abstract] & injur*[Title/Abstract] & defence[Title/Abstract] \\
OR & OR \\
women[Title/Abstract] & defense[Title/Abstract] \\
OR & OR \\
woman[Title/Abstract] & military[Title/Abstract] \\
& OR \\
& army[Title/Abstract] \\
& OR \\
& tactical[Title/Abstract] \\
& OR \\
& recruit[Title/Abstract] \\
& OR \\
& soldier[Title/Abstract] \\
& OR \\
& cadet[Title/Abstract] \\
& OR \\
& trainee[Title/Abstract] \\
&
\end{tabular}

\section{Inclusion and Exclusion Criteria}

Studies were included if they: a) reported on risk factors for injuries sustained by female army personnel, b) were original, peer reviewed research, c) were available in full text, and d) were written in English, or translatable to English by the reviewers. Due to the differences in basic training, entry standards, and occupational demands between services, the focus of this review was narrowed to army personnel only. To gain an understanding of any differences in injury experiences throughout an army career, articles which reported on any time in the career of an army soldier were included. Articles were excluded if: a) they did not report on risk factors separately for female personnel, b) focused on a specific injury type so that a generalisation for all injuries could not be drawn, c) pertained to a more severe level of injury only (e.g., hospitalisation or medical discharge), d) were from a specialised occupation within the Army (e.g. Military Police), or e) were inclusive of part time personnel or military services other than army and data 
for full-time soldiers were not separable for extraction. If articles reported on injury risk of combined cohorts of part time and full-time personnel who undertook the same training program on a full-time, short-term basis, they were retained, and all personnel were treated as if they were full time personnel. Studies which included enlisted part time personnel were excluded due to the risk of confounding arising from the inability to control for the other occupational and recreational activities which they may have concurrently undertaken for many more hours than full-time personnel would have had available for such pursuits.

Search results were imported into Endnote software (Endnote X9, version X9.3.3, Clarivate Analytics, Philadelphia, United States), where duplicates were removed, and articles were screened by title and abstract to assess potential eligibility for inclusion. The inclusion and exclusion criteria were then applied to the remaining articles through detailed review of full texts of the articles by two reviewers. The results of the search, screening and selection processes were recorded in a PRISMA flow chart (19).

Key data from the included studies were then extracted, tabulated, and synthesised. Data of interest included the authors and year of publication, the population size and environment, the risk factors examined, and indicators of the levels of association between specific risk factors and injury risk (for example, odds ratios (OR), relative risks (RR), hazard ratios (HR) or incidence rate ratios (IRR)).

The methodological quality of each included article was appraised using the Critical Appraisal Skills Program (CASP) (20) tool for cohort studies or the AXIS tool for cross sectional studies (21). The CASP has 12 questions, with a maximum possible score of 12, with both questions 5 and 6 containing two sections, but questions 7 and 8 not being scored, due to their subjectivity. The AXIS has 20 questions with a total possible score of 20 . The raw scores from each tool were converted to a percentage and given an accompanying methodological quality rating, whereby scores $<45.4 \%$ were deemed to indicate poor quality, scores $45.4 \%-61.0 \%$ fair quality and scores $>61.0 \%$ good quality [14]. The methodological quality score was included in the data table to allow for the data from each study to be considered in the context of the methodological quality of the respective study.

A critical narrative approach was taken to the qualitative synthesis of findings from the included studies. Meta-analysis was not conducted due to heterogeneity in study designs and methods, injury definitions, outcome measures, and risk factors explored.

\section{Results}

From an initial 1165 articles screened after duplicates were removed, 43 were assessed in full text (Figure 1). From the 43 articles, 18 articles were retained. Among those 18 articles, there were 15 cohort studies $(1,3,9,22-33)$ and three cross-sectional studies $(1,2,34,35)$. Methodological quality overall was considered 'good' (80\%), with cohort studies tending to score higher (82\%), than cross-sectional studies (68\%). Seven studies assessed injury risk in basic training $(16,22,25-27,29,36)$, three studies during Advanced Individual Training (AIT) $(23,24,35)$, three studies in enlisted personnel more broadly $(1,3,34)$, three studies during deployments $(2,32,33)$, one study during officer training $(9)$, and one during the first 
183 days of service (31). Sixteen of the included studies were conducted in the United States military (1-3, $9,22-24,26,27,29,31-36)$, one in the Israel Defense Forces (30), and one in the British Army (25). A total of 17 potential risk factors for injury were investigated, ranging from demographic and anthropometric factors, such as age, height and weight, to physical performance measures, such as aerobic fitness, or muscle endurance, and to historical factors, such as smoking or injury history, previous activity levels, or deployment history. Factors which were similar, such as running a variety of distances, were grouped for comparison in the synthesis below.

\section{Age}

In total, eight studies assessed the influence of age on injury risk in female soldiers $(1,3,23,24,29,34$ 36). There were conflicting results, with four studies finding older age was a risk factor for injury, one finding younger age was a risk factor, and three finding no relationship between age and injury risk. Two studies $(29,36)$ were performed in the basic training context, with varying results. In basic training, female soldiers in the US Army were found to be at a greater injury risk in the age brackets of 25-29.9 years $(\mathrm{HR}=1.30[95 \% \mathrm{Cl}=1.01-1.66], \mathrm{p}=0.04)$ and over 30 years $(\mathrm{HR}=1.43[95 \% \mathrm{Cl}=1.12-1.84], \mathrm{p}<0.01)$ when compared to those aged 17-19.9 years (29). Conversely, Knapik et al (36) in 2001 found that age was not associated with injury risk in female recruits undertaking Army basic training when comparing 17-20-year-old recruits with 20-25- and 35-35-year-old recruits.

Two $(23,35)$ out of three studies performed in the AIT context found that older females were at an increased risk of injury. Women attending AIT in the US Army were significantly more likely to report an injury they had suffered during recruit training which they perceived would affect their current training if they were aged $20-24$ years $(\mathrm{OR}=1.29[95 \% \mathrm{Cl}=1.07-1.56], \mathrm{p}<0.01)$ or over 30 years $(\mathrm{OR}=2.02[95 \% \mathrm{Cl}=$ 1.43-2.87], p<0.01) when compared to those aged 17-19 years (23). Likewise, in a study by Henderson et al (35), female Combat Medic AIT trainees aged more than 25 years had a significantly greater $(p=0.001)$ injury incidence (52.9\%) than those aged between $20-25$ years $(21.3 \%)$ and younger than 20 years (31.2\%). A logistic regression found an OR of 3.5 [95\% Cl $=1.5-8.1]$ when comparing odds of injury in those aged more than 25 years to odds in those under 20 years of age (35). Contrasting the aforementioned results, in a population of females attending Ordinance AIT in the US Military, age was not found to be significantly associated with the risk of a time loss injury when comparing those aged 20$24(\mathrm{HR}=0.89[95 \% \mathrm{Cl}=0.68-1.16], \mathrm{p}=0.39)$ and over 25 years $(\mathrm{HR}=1.18[95 \% \mathrm{Cl}=0.86-1.63], \mathrm{p}=0.32)$ to those aged 17-19 years (reference group) (24).

Three studies were conducted on enlisted personnel after completion of both basic training and AIT (1, 3, 34 ), with these studies finding conflicting results. Age was not found to be associated with injury risk for enlisted females within the US Army in a study by Rappole et al. (1). In the study, the risk of trainingrelated lower extremity injury was not associated with age in 369 female soldiers. Anderson et al. (34) found that younger Army soldiers who were women aged 22 to 26 years were more likely to be injured than both those aged 27 to 30 years and those over 31 years. In total, $57 \%$ of the enlisted females in the 22-26 years age bracket suffered an injury, compared with $52 \%$ in the $27-30$ years age bracket and $48 \%$ in 
the older than 31 years age bracket. This finding was different to that for men in the same study younger enlisted men were found to be less likely to be injured than those who were older, highlighting possible sex differences in the relationship between age and injury risk. However, another study of US Army soldiers by Bedno et al (3) found older females were at a greater risk of lower limb injury and that, when compared to those who were aged 17-23 years, each increasing age group was at a progressively higher risk of suffering a lower limb injury (Table 2).

The conflicting results across these studies regarding the relationship between age and injury risk in female soldiers do not seem to form any clear patterns, and indicate it is currently unclear whether younger or older age is a risk factor for injury and that other factors may be more important predictors of injury risk.

\section{Body Mass Index}

Body Mass Index (BMI) and its relationship to injury risk were considered in seven studies $(1,3,26,27,29$, $35,36)$. BMI was not found to be significantly associated with injury risk in female personnel in all but one (27) of the four studies conducted during basic training $(26,27,29,36)$, in the one study conducted during AIT (35), and in the two studies involving enlisted personnel $(1,3)$. In the basic training environment, injury risk in female US Army recruits was not significantly associated with any quartile of BMI in the study by Jones et al $(26)$. Likewise, in two separate studies, Knapik et al $(29,36)$ found that BMI was not a significant risk factor for injury in female recruits undertaking US Army basic training. Henderson et al (35), found that injury incidence was not significantly different between any levels of BMI during Combat Medic AIT training. BMI was also not a significant predictor of lower limb musculoskeletal injury in the study by Bedno et al. (3), when comparing risk in enlisted female soldiers who were considered to be underweight $\left(<18 \mathrm{~kg} / \mathrm{m}^{2}\right)$, overweight $\left(25-29.9 \mathrm{~kg} / \mathrm{m}^{2}\right)$ or obese $\left(\geq 30 \mathrm{~kg} / \mathrm{m}^{2}\right)$ to risk in those who were considered to be of normal weight $\left(18-24.9 \mathrm{~kg} / \mathrm{m}^{2}\right)$. In contrast, in the same study, BMI was found to be a significant predictor amongst male personnel, with underweight, overweight, and obese male soldiers more likely to suffer a lower limb musculoskeletal injury when compared to those considered to be of normal weight. Rappole et al. (1) found a similar result, where BMI was not found to be associated with injury risk in enlisted female soldiers in the US Army.

In contrast, in a large study of 41,727 female recruits undertaking basic training, Jones et al (27) did find a significant bimodal relationship, with low and high BMI associated with increased injury risk. Both the low BMI group of $<20.7 \mathrm{~kg} / \mathrm{m}^{2}$ and high group of $>25.6 \mathrm{~kg} / \mathrm{m}^{2}$ were found to be at an increased risk of injury when compared to those considered to be in the 'normal' range for BMI. This finding suggests that perhaps BMI has not been identified as a significant risk factor in studies with smaller sample sizes due to lower statistical power of those studies to detect such a relationship. However, overall, the volume of evidence suggests that BMI is not a strong and consistent risk factor for injury in female soldiers and that other factors may be more important in predicting injury risk.

\section{Body Fat}


Body fat percentage is thought to be a more accurate representation of body composition than BMI (37) and was investigated in five studies $(1,26,30,34,36)$, with four studies $(1,26,34,36)$ finding no relationship between body fat percentages and injury risk. Body fat percentage was found not to be a predictor of injury risk during basic training for female soldiers in the US Army in two studies $(26,36)$, and was also not found to be associated with injury risk in a study of enlisted female US Army personnel (1). In a study by Anderson et al., (34) no difference in injury rates was found between tertiles of body fat percentage in female soldiers from the US Army. However, in male soldiers, those in the middle and highest tertile were injured more commonly than those in the lowest tertile $(\leq 29.05 \%)$, suggesting while body fat percentage might be a risk factor for male soldiers, it is not an important risk factor in female soldiers.

In contrast to this finding, Kodesh et al (30) found a significant difference $(p=0.047)$ in body fat levels between those female soldiers who were injured (median 23.7\%) when compared to those who were not injured (median 22.5\%), during a three month Combat Fitness Instructor Course in the IDF. Nevertheless, the volume of evidence suggests that body fat percentage, in general, is not a strong risk factor for injury in female soldiers.

\section{Body Mass}

Body mass was examined as a potential risk factor for female soldiers in three studies $(26,35,36)$, with only one finding a significant relationship between body mass and injury risk (35). Weight was not found to be a risk factor for injury during army basic training in the US Army in the study by Jones et al (26) nor in the study by Knapik et al (36). In a separate study, female personnel who weighed between 69 and $95 \mathrm{~kg}$ had a greater incidence of injury during Combat Medic AIT when compared to those weighing less (35). A regression analysis found an OR for injury of $2.4[95 \% \mathrm{Cl}=1.1-5.0]$ for those of that weight category when compared to lighter female soldiers (35). Noting the broad confidence interval for this OR and the non-significance of body weight as a risk factor for injury in female recruits in the other two studies, it would appear body mass is unlikely to be a strong risk factor for injury in female soldiers.

\section{Height}

Only one study (26) of four that investigated body height as a potential risk factor $(9,26,35,36)$ found a relationship between height and injury risk in female soldiers. Jones et al (26) found that the females in the quartile of shorter stature $(\sim 164 \mathrm{~cm})$ were at a greater risk of injury during basic training than the taller $75 \%(\mathrm{RR}=1.7$ [95\% $\mathrm{Cl}=1.2-2.4], \mathrm{p}=0.02)$. Knapik et al (36) found no significant relationship between stature and injury risk during Army basic training and, likewise, Henderson (35) found no significant differences in injury incidence between female soldiers of varying heights during Combat medic AITs in the US Army. Bijur et al (9) found no relationship between height and injury risk in West Point Officer cadets undertaking their basic training. Height, therefore, does not appear to be a strong risk factor for injury in female soldiers.

\section{Smoking}


Five $(3,22,24,29,36)$ out of seven of the included studies that investigated smoking as a potential risk factor $(3,22-24,29,35,36)$ found that smoking was a risk factor for injury among female soldiers.

Altarac et al (22) found that female soldiers who had smoked prior to enlisting in the US Army presented with an increased risk of injury overall $(\mathrm{OR}=1.61$ [95\% $\mathrm{Cl}=1.19-2.17]$. This was not found for traumatic injury types $(\mathrm{OR}=1.05[95 \% \mathrm{Cl}=0.67-1.64])$ but was evident for overuse type injuries $(\mathrm{OR}=1.71[95 \% \mathrm{Cl}=$ 1.26-2.31]), and injuries which were more severe, resulting in greater than 'one day' of lost time $(\mathrm{OR}=1.44$ $[95 \% \mathrm{Cl}=1.02-2.02]$ ) or 'greater than six days' of lost time ( $\mathrm{OR}=1.75[95 \% \mathrm{Cl}=1.21-2.51])$. Female recruits in US Army basic training who smoked $>20$ cigarettes per day were found to be at a significantly greater risk of injury than female recruits who did not smoke ( $R R=4.4[95 \% \mathrm{Cl}=1.9-10.0], \mathrm{p}<0.01)(36)$. In the same study, cigarette smoking was also found to be an independent risk factor for time loss injury in a subsequent multivariate regression analysis $(R R=2.0[95 \% \mathrm{Cl}=1.2-3.5], \mathrm{p}=0.01)$. A later study in the same environment found an increased risk of injury even with fewer cigarettes per day, with as few as 1-9 cigarettes per day leading to an increased injury risk in female soldiers $(\mathrm{HR}=1.44[95 \% \mathrm{Cl}=1.19-1.73]$, $\mathrm{p}<0.01$ ) when compared to those who did not smoke (29). In a similar manner, Bedno et al. (3) found that female US Army soldiers who were currently serving and smoking were at a greater risk of lower limb injury (OR $1.30[95 \% \mathrm{Cl}=1.23-1.36]$ ) than serving female soldiers who were not smoking.

Grier et al. (24) reported that, overall, females who were both occasional $(\mathrm{HR}=1.08$ [95\% $\mathrm{Cl}=0.67-1.73]$, $\mathrm{p}=0.77)$ and frequent smokers $(\mathrm{HR}=1.27[95 \% \mathrm{Cl}=0.98-1.63], \mathrm{p}=0.07]$ prior to initial training were not at a significantly increased risk of time loss injury when compared to those who did not smoke. However, when the female soldiers were stratified by the number of cigarettes smoked, a significantly greater risk was evident for those who smoked 20 cigarettes or more per day in the 30 days prior to basic training when compared to those who smoked fewer than 20 cigarettes per day $(\mathrm{HR}=1.71$ [95\% $\mathrm{Cl}=1.12-2.59]$, $\mathrm{p}=0.01$ ). In contrast, Grier et al. (23), in their earlier work published in 2010 , found that among female soldiers, neither occasional smokers nor frequent smokers were at a significantly greater risk of injury when compared to those who did not smoke, and that comparisons of groups based on number of cigarettes smoked per day did not suggest increases in smoking were associated with an increased risk of injury. Likewise, Henderson et al (35) found no evidence that those female soldiers who reported they were current smokers were at an increased risk of injury during combat medic AIT when compared to those who were not $(p=0.190)$. The volume of evidence nevertheless suggests that smoking is a significant risk factor for injury in female army personnel.

\section{Previous Injury}

Four studies examined the association between history of previous injury and future injury risk in female soldiers $(2,24,29,35)$, with three $(2,24,29)$ showing a significant relationship. Female personnel who had suffered a previous self-reported injury were found to be at an increased risk of subsequent injury during US Army Basic Training ( $R R=1.41$ [95\% Cl = 1.13-1.75], $p<0.01$ (29). Likewise, those who had reported a previous injury were at a greater risk of suffering a 'time loss' injury than those who did not report a previous injury during US Army Ordinance school training $(\mathrm{HR}=1.67[95 \% \mathrm{Cl}=1.21-2.30], \mathrm{p}<0.01)$ (24). Enlisted female US Army soldiers were shown to be an increased risk of injury if they had a history 
of injury (RR=2.6 [95\% Cl =2.06-3.28]) (2). Conversely, work by Henderson et al (35) found that an injury suffered in basic training did not lead to a higher injury incidence in AIT training for combat medics. In the AIT training, those who reported a previous injury had an injury incidence of $29.5 \%$, whereas those who reported no injury, had an injury incidence of $37.4 \%(p=0.198)$.

\section{Current Physical Activity}

There are conflicting results regarding the association between reported current level of physical activity performed by female soldiers and injury risk. Rappole et al. (1) found that female soldiers doing more unit physical training (PT), but less personal running and interval training, were at an increased risk of injury. The female enlisted US Army soldiers who were doing unit PT more than once a week were reported to be at a greater risk of injury than those who were doing fewer sessions $(\mathrm{OR}=1.96[95 \% \mathrm{Cl}=1.20-3.21)$, $p<0.01)(1)$. However, those who were not doing personal running of at least one mile per week or personal interval training at least once per week were found to be at increased risk of injury when compared to those who were doing one of these types of personal training, though the differences were of marginal statistical significance $(\mathrm{OR}=1.57$ [0.98-2.52], $\mathrm{OR}=1.64[95 \% \mathrm{Cl}=1.00-2.71]$, respectively).

Conversely, in the study by Roy et al. (2), enlisted female soldiers in the US Army were found to be at an increased risk of injury if they did not do any unit runs each week, when compared to those who did one to two runs per week ( $\mathrm{RR}=1.53[95 \% \mathrm{Cl}=1.07-2.19])(2)$. In addition, those female soldiers who did one to two personal resistance training sessions per week were reported to be at a greater injury risk than those who did none $(\mathrm{RR}=1.42[95 \% \mathrm{Cl}=1.08-1.87])$.

\section{Previous Physical Activity}

Four studies assessed the relationship between previous levels of physical activity performed by female soldiers prior to basic training $(26,29,36)$ and AIT $(35)$ and injury risk. Only one of the studies conducted during basic training (29) showed an association between self-reported previous activity and injury risk; those who reported that they participated in sport or exercise less than once per week prior to basic combat training were found to be at a greater risk of injury than those who reported greater than five episodes of sport or exercise per week $(R R=1.41[95 \% \mathrm{Cl}=1.09-1.82], p<0.01)$. A similar result was seen for self-reported running or jogging in the same study, with those reporting a history of less than one session per week being at a greater risk of injury than those two reported five or more sessions per week $(\mathrm{RR}=1.62[95 \% \mathrm{Cl}=1.16-2.27], \mathrm{p}<0.01)(29)$. Conversely, the self-reported amount or duration of physical activity prior to enlistment was not found to be associated with injury incidence in female soldiers undertaking combat medic training (35), or in female recruits undertaking basic training in two other studies $(26,36)$.

\section{Deployment}

The relationship between deployment history and injury risk was investigated in two studies $(2,3)$, while individual risk factors for injury during operations in Afghanistan were the focus of two other studies (32, 
38). Female soldiers of US Army units who had not been deployed were found to have higher injury rates than those who had been deployed at least twice $(\mathrm{RR}=1.48[95 \% \mathrm{Cl}=1.02-2.13])(2)$. A similar finding was reported by Bedno et al. (3), whereby those who had been on one deployment were less likely to be injured than those who had not been deployed $(\mathrm{OR}=0.65[95 \% \mathrm{Cl}=0.58-0.72], \mathrm{p}<0.001)$.

\section{Heavy Occupational Tasks}

Whilst on deployment, there have been several risk factors reported as increasing the likelihood of injury among female soldiers. Self-reported physically demanding work, walking more than four miles per day, wearing loads greater than 30 pounds, carrying loads for more than 25 feet, lifting objects to waist height or lower, wearing armour for more than an hour a day, wearing a backpack, and lifting an average weight of greater than 50 pounds were all found to be associated with an increased risk of injury in female soldiers deployed in Afghanistan, in two studies by Roy et al $(32,38)$.

\section{APFT}

Two studies $(2,3)$, both involving enlisted, female army personnel, investigated the relationship between injury risk and overall score on the Army Physical Fitness Test (APFT), comprised of a 2-mile run, pushups, and sit-ups in 2 minutes. Female soldiers who had a score lower than 270 points on the APFT were found to be at an increased risk of lower limb injury, with a gradual increase in risk for those scoring 240269 points (OR 1.11 [95\% Cl=1.03-1.20], $\mathrm{p}=0.006), 215-239$ points $(\mathrm{OR}=1.17$ [95\% Cl = 1.09-1.27], $\mathrm{p}<0.001)$ and less than 215 points $(\mathrm{OR}=1.45[95 \% \mathrm{Cl}=1.35-1.57], \mathrm{p}<0.001)(3)$. Roy et al $(2)$ found an increased risk even in those scoring up to 290 points, with 290 points being used as a threshold level beyond which risk of injury was lower than that observed in those scoring below that score (Table 2).

\section{Push-ups}

Seven studies investigated the relationships between push-up performance and injury risk in female personnel. In trainees, three $(27,29,36)$ of four studies $(26,27,29,36)$ reported a relationship between low push-up performance and injury risk during basic training while the remaining study failed to find a significant association.

Of the studies investigating the trainee populations, a study published in 1993 by Jones et al (26) reported no significant differences in injury incidence in female trainees completing basic training in the US Army regardless of quartile of push-up performance. A more recent study by the same authors (27) found an increase in injury risk from $31.6 \%$ in those female recruits in the quintile who could perform the most push-ups to $48.8 \%$ in the quintile with the lowest push-up performance (RR=1.5 [95\% Cl $=1.49$ $1.61])$, with a significant trend linking increasing injury risk to decreasing push up ability $(p<0.00001)$. In the aforementioned more recent study by Jones et al (27), low BMI combined with low push-up ability were also found to be associated with increased injury risk with an injury rate of $50 \%$ in basic training for this group ( $\mathrm{RR} 1.7$ [95\% $\mathrm{Cl}=1.6-1.9]$ ) when compared to those with normal $\mathrm{BMI}$ in the highest push-up quintile. Likewise, female recruits in US Army Basic Training who performed fewer than 14 push-ups were 
found to be at an increased risk of injury when compared to those female recruits who completed 14 or more push-ups $(R R=1.6[95 \% \mathrm{Cl}=1.1-2.4], \mathrm{p}=0.02)(36)$. A later study in the same environment found similar results, with female trainees who could only perform between 0-4 push-up repetitions in a 2 minute period being at an increased risk of injury when compared to female trainees who could perform more than 23 repetitions $(\mathrm{HR}=1.92[95 \% \mathrm{Cl}=1.41=2.59], \mathrm{p}<0.01)(29)$.

A study by Grier et al (24), involving 498 female soldiers, investigated push-up performance and injury risk during US Army AIT at the Ordinance School. The authors found that females who could perform more than 37 push-ups were at a decreased risk of time loss injury when compared to those who could perform between 24 and 30 repetitions $(H R=1.44$ [95\% $\mathrm{Cl}=1.02-2.04], p=0.04)$ and less than 23 repetitions $(\mathrm{HR}=1.47[95 \% \mathrm{Cl}=1.03-2.09], \mathrm{p}=0.03)(24)$.

Both studies of enlisted female Army personnel serving after completion of initial training failed to find any association between push-up performance and injury risk $(1,34)$. The number of push-ups completed as part of the APFT by enlisted female soldiers in the US Army was not found to be associated with risk of injury (1). In line with that finding, no difference was found in injury rates between any tertiles of pushups within female enlisted US Army soldiers; this contrasts with the finding for male soldiers, in whom risk of injury was found to be increased for male soldiers who performed less than 62 repetitions $(\mathrm{RR}=1.31$ [95\% $\mathrm{Cl}=1.19-1.44], \mathrm{p}<0.01)$ (34). The volume of evidence suggests that low push-up performance may be a risk factor for injury within female soldiers during basic training but potentially not for female soldiers serving after completion of basic training.

\section{Sit-ups}

Four studies examined sit-up performance in two minutes as a potential risk factor for injuries in female soldiers during basic training $(26,27,29,36)$, one during AIT $(24)$, and two in enlisted soldiers $(1,34)$. Two studies conducted by Jones et al in 1993 (26) and 2017 (27) did not find an association between sit-up performance and injury risk in basic training. Likewise, Knapik et al (36) found that the number of sit-up repetitions completed was not associated with injury risk during US Army Basic training in 2001. Later, in 2009, Knapik et al (29) found that the number of sit-ups in 2 minutes was a risk factor for injury, with risk increased in those female personnel who could only perform 0-20 repetitions ( $\mathrm{HR}=1.75[95 \% \mathrm{Cl}=1.29$ 2.37] $p<0.01$ ), when compared to those who could perform more than 47 repetitions.

Later in the training progression of a soldier, the maximal number of sit-up repetitions was not found to be a risk factor for injury in female soldiers undertaking Ordnance School AIT in the US Army. In the study by Grier et al (24), female soldiers who could perform between 0 and 23 sit-up repetitions were not found to be at a significantly increased risk of injury compared to those who were able to do more than 68 repetitions ( $\mathrm{HR} 1.28$ [95\% $\mathrm{Cl}=0.91-1.76], \mathrm{p}=0.16)$.

Female enlisted US Army personnel who performed in the bottom two thirds of sit-up repetitions for the APFT were found to be at an increased risk of injury when compared to those in the upper third (OR = $1.68[95 \% \mathrm{Cl}=0.96-2.93])$, however APFT sit-up repetitions did not feature in a multivariate regression 
model for prediction of injury in that population (1). Enlisted female soldiers who could not perform more than 62 sit-ups were found to be at a greater risk of injury than those who could perform more than 62 $(\mathrm{RR}=1.35[95 \% \mathrm{Cl}=1.01-1.80], \mathrm{p}=0.03)$ (34). A similar relative risk of injury was found in enlisted men who were unable to complete that number $(\mathrm{RR}=1.31[95 \% \mathrm{Cl}=1.19-1.44], \mathrm{p}<0.01)(34)$. Overall, the volume of evidence suggests sit-up performance may be a weak predictor of injury risk in female soldiers, but the findings are inconsistent.

\section{Strength, Power and Speed Assessments}

Kodesh et al. (30) conducted a barrage of power and speed assessments on female soldiers completing a combat fitness instructors' course in the Israel Defense Forces (IDF). Neither the $10 \mathrm{~m}$ sprint time nor any parameters measured for the drop jump and the counter movement jump were found to be significantly associated with injury risk. The single leg triple hop distance was found to be significantly associated with injury risk ( $p=0.029$ on the left and $p=0.047$ on the right). Knapik et al (36) also assessed a variety of strength and power measurements in female recruits undertaking basic training, including incremental dynamic lift strength, upper and lower body strength, upright pull static strength, and a vertical jump assessment, and found no relationship between any measurement and injury risk. Overall, the evidence at this stage does not support or suggests only weak associations between low levels of strength, power or speed and injury risk in female military personnel.

\section{Flexibility}

Knapik et al (36) assessed flexibility in females undertaking basic training with the sit-and-reach test and found no significant difference in injury risk for those who scored less $(-6 \mathrm{~cm}$ to $31 \mathrm{~cm} \mathrm{RR}=0.7[95 \% \mathrm{Cl}=$ 0.4-1.3], $p=0.27)$, or more ( $40-55 \mathrm{~cm} \mathrm{RR}=0.9[95 \% \mathrm{Cl}=0.5-1.5], \mathrm{p}=0.64)$ than the referent group of 32$39 \mathrm{~cm}$. In contrast, the male trainees did show a relationship between their sit-and-reach performance and injury risk, with a bimodal curve evident in which those who were most and least flexible were at greater risk of injury.

\section{Aerobic Fitness}

Aerobic fitness, as measured by runs of varying distances, including $3.2 \mathrm{~km} / 2 \mathrm{mile}(2,24,27,29,36)$, $2.4 \mathrm{~km} / 1.5 \mathrm{mile}(25), 2 \mathrm{~km}$ (30), or 1 mile (26), a 5 minute step test (31), or average time per mile (9), was found to be related to injury risk in eleven studies that investigated this potential risk factor for injury, and at all stages of a female soldiers career. The one exception was the study by Rappole et al (1), in which the run distance was 2 miles, and completed by 369 female soldiers.

Knapik et al (36) in 2001 found that the slowest two quartiles of $3.2 \mathrm{~km}$ run times were associated with increased risks of injury in female soldiers when compared to the fastest quartile of 10.38-15.40 mins ( $R R=1.6$ [95\% Cl = 1.0-2.3], $\mathrm{p}=0.04, \mathrm{RR}=1.9$ [95\% $\mathrm{Cl}=1.2-2.8], \mathrm{p}<0.01$, respectively). A low peak relative $\mathrm{VO}_{2}$, in the range of $29.9-37.0 \mathrm{ml} / \mathrm{kg} / \mathrm{min}$ was also found to be an independent risk factor for time loss injury in a multivariate cox regression $(\mathrm{RR}=2.8[95 \% \mathrm{Cl}=1.4-5.6], \mathrm{p}<0.01)$. A similar result was found by 
Knapik et al (29) again in 2009, with the slower quartile exhibiting an elevated injury risk ( $\mathrm{HR}=2.18$ [95\% $\mathrm{Cl}=1.60-2.98], \mathrm{p}<0.01)$ when compared to those with the quicker run times over 2 miles.

A similar result has also been reported in the British Army for $2.4 \mathrm{~km} / 1.5$ mile run times, with female recruits who were injured having a mean time of 12 minutes and 43 seconds, compared to those who were not injured achieving 12 minutes 13 seconds. A subsequent regression analysis found that every 10 second increase in run time was associated with an $8.3 \%$ greater injury risk (25). This is in line with the finding of increased incidence of time loss injuries in the slower two quartiles of the 1 mile run during US Army basic training $(\mathrm{RR}=2.40[95 \% \mathrm{Cl}=1.2-4.8]$ and $\mathrm{RR}=2.18[95 \% \mathrm{Cl}=1.1-5.0]$ respectively) (26). $\mathrm{A}$ more recent study by Jones and colleagues (27) showed the same trend of increasing injury incidence with slower run times. The quintile with the fastest 2-mile run time ( $<16.2$ minutes) had an injury incidence of $26.5 \%$ across the basic training period, which increased to $56.0 \%$ in the slowest quintile (>19 minutes), with an associated risk ratio of $2.2[95 \% \mathrm{Cl}=2.0-2.2]$. When combined with a low BMI, those who had a slower run time had an injury incidence of $63.1 \%(\mathrm{RR}=2.6[95 \% \mathrm{Cl}=2.3-2.8], \mathrm{p}<0.00001$, when compared to those with normal BMI and fastest run time).

Female soldiers attending Ordinance School AIT in the US Army were found to be at increased risk of time loss injury if they ran slower than 19.39 minutes for the 2-mile run, when compared to those who completed it in less than 17 minutes $(\mathrm{HR}=2.04$ [95\% $\mathrm{Cl}=1.45-2.88], \mathrm{p}<0.01)(24)$. An increased risk was also associated with the 17.01-18.08 minutes timeframe $(\mathrm{HR}=1.46[95 \% \mathrm{Cl}=1.02-2.08], \mathrm{p}=0.04)$, but not in the 18.09-19.38-minute timeframe $(\mathrm{HR}=1.27$ [95\% Cl $=0.88-1.83], \mathrm{p}=0.21)$. Kodesh (30) also reported significant differences in injury risks associated with different $2 \mathrm{~km}$ run times $(\mathrm{OR}=1.007[95 \% \mathrm{Cl}=1.001$ 1.014], $p=0.022$ ), with a median time of 658 seconds amongst those who were injured, which was significantly slower than the median time of 640 seconds for those who reported no injury. The authors of that same study performed a Receiver Operating Characteristic analysis and identified an optimal diagnostic cut off at 11 minutes and 33 seconds for the $2 \mathrm{~km}$ run, which predicted injury with a sensitivity of 0.40 and specificity of 0.86 . Likewise, females enlisted in US Army units who ran 2 miles in 17-18 minutes were at an increased risk of injury when compared to those who were faster $(\mathrm{RR}=1.71[95 \% \mathrm{Cl}=$ 1.07-2.73]) (2).

The same risk factor appears to exist for cadets undertaking officer training. Female West Point cadets who had slower mean run times per mile were at a greater risk of injury, with injury rates increasing from 42.1 injuries per 100 cadets for those whose mean run time was 7.2 minutes, to 126.3 injuries per 100 cadets for those whose mean run time was 9.8 minutes (9).

Krauss et al (31) explored the interaction between body fat, aerobic fitness, and injury risk in female US Army trainees. They found that those who were deemed to be unfit, as measured by a five-minute step test, were more prone to both non stress fracture injury (IRR $=1.32[95 \% \mathrm{Cl}=1.14-1.53]$ and stress fracture injury (IRR $=1.62$ [1.19-2.21] than those who were fit. Those who were fit but exceeded body fat limits had an increased risk of non-stress fracture injury (IRR $=1.27[95 \% \mathrm{Cl}=1.07-1.50]$ but appeared to be less prone to stress fracture (IRR $=0.79[95 \% \mathrm{Cl}=0.49-1.28]$ when compared to females who were 
both fit and of optimal body fat composition. Those who met the body fat limits but were unfit tended to suffer more stress fractures (IRR $=1.62[95 \% \mathrm{Cl}=1.19-2.21])$. Conversely, Rappole et al (1) did not find 2mile run times to feature in the multivariate model which was predictive of lower extremity, training related injury among enlisted women $(n=369)$ in the US Army, suggesting that in enlisted women serving in the army, aerobic fitness levels may not be strong predictors of injury risk and other factors may be more important in predicting injury risk.

\section{Movement Assessments (FMS \& Y Balance)}

One study examined the relationships between Functional Movement Screen (FMS) results and injury during a combat fitness instructors course within the Israel Defense Forces (IDF) (30). No significant difference was found in FMS scores between those injured (mean FMS score = 16 [IRQ=12.75-18.0]) and not injured (mean score $=16$ [13.25-17.0]). In attempting to find an optimal cut-off score in the FMS which could be used for prediction of injury risk, Kodesh et al. (30) found that with a score of 12, they only achieved $24 \%$ sensitivity and $83 \%$ specificity, while a score of 14 led to $42 \%$ sensitivity and $63 \%$ specificity. Their regression model for prediction of injury risk based on FMS scores was not statistically significant, with an OR of 0.95 ( $[95 \% \mathrm{Cl}=0.87-1.1], \mathrm{p}=0.77)$, leading the authors to suggest that the FMS was not an effective tool in predicting injury risk in female soldiers in the IDF.

Single leg balance ability and its relationship to injury amongst female soldiers deployed in Afghanistan was assessed in one study (32). Roy et al (32) found that those female soldiers who had a composite score of $\leq 95.23$ in the $Y$ Balance assessment were at a significantly greater risk of injury than those who scored above this number $(\mathrm{RR}=1.71[95 \% \mathrm{Cl}=1.13-2.60]$. There were no other studies which reported associations between injury risk and results of any other movement assessments.

\section{Discussion}

The aim of this review was to identify, analyze, and synthesize studies which reported on injury risk factors specific to female soldiers, to inform targeted injury reduction programs. Most of the included studies (16/18) were from the US Army, with a variety of environments studied, from basic training, to AIT, and to enlisted and deployed personnel. Smoking, previous injury, no history of deployment, heavy occupational tasks, lower levels of aerobic fitness, and lower numbers of push-up repetitions are all associated with increased injury risk in female soldiers. Despite previous research reporting an elevated risk being associated with these factors for injury amongst male soldiers (27), age, height, body fat, high or low BMI and body mass do not appear to be consistent risk factors for injury among female soldiers. There appears to be minimal evidence that current levels of activity, sit-up ability, assessments of strength, power or speed, or movement assessments are associated with injury risk. Flexibility and previous levels of activity appear not to be related to injury risk in female personnel. 
Age has been inconsistently associated with injury risk in female military personnel. Three of four studies within basic training and one of two articles in AIT showed that higher age was associated with an increased injury risk. The one study in Ordinance AIT which showed no difference between age groups in injury risk may be due to the age groups selected in the analysis. The upper age bracket of $>25 y e a r s$ included personnel comparably younger than the upper age group of $>30$ years used in basic training studies and may have therefore reduced the magnitude of the association observed between age group and injury risk. The study by Henderson et al (35) used the same age bracket in Combat Medic AIT, however, due to the less physically arduous nature of that AIT training, it is difficult to make direct comparisons between it and other AIT training. This supposition is supported by Tomes et al. (39), who noted that the associations between injury risk and fitness factors in tactical populations were influenced by the training being undertaken by personnel.

Of the two studies conducted in enlisted personnel who were not undertaking a training program, one found that younger age was a risk factor for injury, and one found no difference in risk across age groups. This latter finding might be explained in part by the increase in age that typically accompanies higher ranks and the decrease in physical tasks undertaken by those of a higher rank, which has been demonstrated in previous studies (40). It has been reported that for each individual increase in rank for female soldiers, the injury risk decreases $14 \%$ (2). When soldiers perform the same tasks, such as during basic training and AIT, injury risk is often higher in older personnel (35). Older age is typically associated with declines in cardiorespiratory fitness, which in itself is associated with an increased risk of injury (41), and may explain the increased injury risk during training (42). In contrast, changes in physically demanding tasks with increased rank may explain the lack of associations between age and injury in serving populations. Across all studies, a phenomenon similar to the healthy worker effect may also influence the results, whereby those who have been injured may have been discharged from the military, leaving only those who are more injury resilient to form older study populations; further affecting findings regarding age as a risk factor for injury (43).

\section{BMI, Body Fat and Body Mass}

Only one of the six studies which reported on BMI found an association with injury risk in female soldiers. Jones et al (27) proposed that lower BMI may be more problematic than a higher BMI due to its association with lower muscle mass. The authors of the study also suggested that BMI interacted with fitness, which was deemed to be more critical, and that those with a high BMI would be at less risk if they had adequate aerobic fitness. The higher levels of BMI may be associated with an increased amount of lean muscle mass and BMI's inability to offer insight into body composition make it problematic for drawing meaningful conclusions regarding underlying mechanisms for any association with injury risk. No other included study in this review found BMI to be a risk factor for injury in female soldiers.

Only one study reported body fat to be associated with injury risk in females (30). The female soldiers in that study were much leaner $(22.5 \%)$ than those in other studies $(25.2 \pm 9.36 \%(26)$ to $31.7 \pm 5.3 \%(34))$, and this may have affected their findings. Body composition may also be related to specific types of injuries, 
as opposed to injuries in general. As Krauss et al (31) found, female soldiers with high levels of body fat suffered more non-stress fracture injuries and were at a lower risk of stress fractures than those with lower levels of body fat. The results of that study may not be generalizable, however, as it was inclusive of individuals who exceeded the body fat limits for entry to the army and who were granted a waiver for a short period of time (31). Body fat was associated with injury risk in males in two studies $(26,34)$, and it is not clear why this risk factor is different between males and females. Although errors arising from body fat being estimated in most instances with various equations or from four-site skinfold assessments may contribute to variation in study findings, body fat was not related to injury in the study by Knapik et al (36), when using DEXA to determine body composition.

Only one study found a relationship between body fat and injury risk in female soldiers (35). The authors of that study proposed that this finding was due to greater body forces arising from the extra mass, potentially making those with greater levels of body fat more susceptible to injury (35). Conversely, those with greater mass, BMI or body fat may be more musculoskeletally resilient, provided they possess adequate aerobic fitness (34).

\section{Height}

Of four studies $(9,26,35,36)$, three failed to find any relationship between height and female soldier injury risk $(9,35,36)$. There was only one study, the earliest of the four studies, conducted in 1993, which found height to be related to injury risk (26). Injuries in females who were shorter were linked to overstriding when marching at the rear of formations in a study in 2000 (44), and subsequently adequate steps may have been put in place to ensure shorter individuals set the pace of march at the front of a formation. This may explain the lack of association between height and injury risk in female soldiers since the early 1990's. Conversely, there may be a progressive increase in mean heights of the population, which has been reported in United States military cohorts and might reduce the impact of this risk factor (45).

\section{Smoking}

Smoking appears to be a risk factor for injury amongst female soldiers, with most studies finding a significant association between smoking and injury risk, particularly for overuse type injuries (22). Smoking is reported to affect bone mineral density, have effects on fibroblasts - affecting both the healing of injuries and the tissue repair process - and contribute to overall injury risk $(22,24)$.

Despite not initially finding a relationship between smoking status and injury risk (23), Grier et al (24) found that female soldiers who smoked more than 20 cigarettes per day were at an increased risk of injury during AIT when compared to those who smoked less. The lack of association in the earlier study by Grier et al (23) may be explained by the self-reporting of injuries and the question posed to participants of whether they thought their injuries may affect their training. Attendees to AIT may be reluctant to disclose an injury or they might perceive that their injury may not affect their training, given they may not know much about its composition or the variation in physicality and length of AIT courses. Likewise, 
recruits are not able to smoke during either basic training or AIT, which may have led to a 'wash out' of the detrimental effects of smoking over this period (35).

\section{Previous Injury}

An injury history appears to be associated with risk of future injury in female soldiers, with three of four included studies showing a relationship with injury risk. The one study which did not show a significant relationship between previous injury and injury risk during AIT may have had this finding due to the selfreporting of injury, the short duration of the study, or the reported lower physical intensity of combat medic training when compared to other forms of military training (24). Injuries during basic training are reported to be suffered at a much higher rate than at other times during a military career (46), and this could potentially lead to a career full of injuries if these initial injuries predispose female soldiers to subsequent injuries (47). In military populations, previous injuries both at the same body location and at adjacent locations are reported to lead to a ten-fold increase in future injury risk $(48,49)$. Research has shown that once an injury occurs during load carriage, subsequent injury risk is increased by $30 \%$ within the next 12 months, and up to $50 \%$ more likely at some stage during a soldiers career (50). The same relationship is seen in sporting contexts (51), and with sporting participation being a notable cause of injury in both male and female military personnel post-basic-training, reduction of sporting injuries should also be a priority (52). Emphasis should therefore be placed on ensuring injuries, when they do occur, are fully rehabilitated prior to female (and male) soldiers returning to training or active duty, to minimise the chance of further injury.

\section{Current and Previous Activity}

Of the three included studies which assessed the level of activity performed by female soldiers prior to basic training, two of them asked participants to rate themselves compared to others. It is unclear whether this perception of one's own level of activity biases the result, as Knapik et al (29) found that there were no significant increases in injury risk for those who rated themselves at any level compared to others. However, research does indicate that military personnel are generally reliable when self-rating their fitness (53). When questions pertaining to frequency of exercise or sport, and history and frequency of running were posed, significant increases in injury risk were found in those who reported doing less (29). Self-reported level of physical activity prior to joining the army was not found to be associated with injury risk in female soldiers during subsequent AIT training, proposed to be due to normalization of physical activity levels through the 8 weeks of basic training (35). There may have also been a basement effect, whereby recruits were required to be fit enough to pass the entry tests, thereby having the requisite level of fitness to minimise injury risk.

Aerobic fitness, muscular strength and endurance are occupationally relevant to female soldiers and play a role in reducing the risk of injury (54). Studies included in this review found that enlisted females who did not perform their own running or interval training and participated in unit runs were found to be at an increased risk of injury $(1,2)$. Conversely, both unit (1) and personal (2) resistance training were found to increase risk of injury for female enlisted soldiers. Resistance training is important for female soldiers, as 
it increases lean muscle mass and strength (1). Roy et al. (2) found that those who were doing 1-2 session of individual resistance training were more commonly injured than those doing none or at least three sessions; leading the authors to recommend further research with a larger sample size (the sample size in their study was 625 women). It has been proposed that perhaps more instruction in resistance training is needed for female soldiers (1), however, it is unclear if it is simply the addition of resistance training to the already physically demanding nature of deployment which contributes to overall injury risk, as opposed to the resistance training itself - a supposition supported by the work of Goodall et al., (55) who found that the inclusion of balance and agility training in addition to current training actually increased injury risk rather than decreasing it. Unit resistance training, in the study by Rappole et al., (1) may not have been individualized, and therefore contributed to, as opposed to decreased, overall injury risk. This highlights once again, the importance of ability-based training within military personnel.

\section{Deployment}

The reason for deployment being protective against injury in female soldiers may relate to several factors. Soldiers must reach a certain level of fitness to be deployed, and therefore those who do not meet these standards or are injured, will likely not be deployed. Thus, a pseudo healthy worker effect may be present. Research has shown that while personnel are on deployment, 2-mile run times decreased by 50 seconds, due to an increase in personal running (56). This may be due to the ability of deployed personnel to self-pace their training, as formal PT is atypical on deployment, which has been shown to improve fitness and decrease injury risk (57). A decrease in unit PT, combat training and sport may also explain some of the decline in injury rates, given that these are leading causes of injury $(2,58)$.

\section{Heavy Occupational Tasks}

Whilst on deployment, there are a range of physical and mental stresses which a soldier is exposed to due to a lack of resources, austere environmental conditions, and the potential for hostile contacts (56). Despite great efforts directed at reducing combat-based injuries and fatalities, training related injuries and other non-combat injuries are typically responsible for a higher number of hospitalisations than combat related injuries (5-7). Female military personnel appear to be at an increased risk of injury while on deployment when lifting, carrying, and wearing load $(32,33,38,59)$. It is an occupational requirement for soldiers working in combat zones to carry load, including body armour, which for females, can be plagued by issues with equipment fitting and conforming to the female body (60), given that it is typically designed for males. Despite reports of significantly lower absolute loads being carried by female soldiers, their relative loads were the same as for male soldiers in a study conducted prior to female soldiers entering combat trades (61). As such, the removal of combat operation restrictions for female soldiers may see female soldiers carrying similar absolute loads but heavier relative loads, a supposition supported by research in law enforcement (62). Furthermore, female soldiers have been shown to be working at a higher work effort in carrying equivalent absolute load to male soldiers, due to differences in absolute fitness and body composition (15). The potential increases in absolute load, leading to a higher 
relative load, and resulting requirement for female soldiers to work at a higher work effort carrying these loads could be anticipated to increase injury risk during combat-specific training and on deployments.

Both carrying and lifting these heavy loads on deployment have been highlighted as a risk factor for injury in female personnel $(32,33)$. Other deployment related risk factors for injury include wearing equipment including backpacks and armour for longer durations, and work which is considered to be heavy and physically demanding $(32,33)$.

\section{APFT}

Poor scores on the APFT were associated with injury risk for female soldiers $(2,3)$. It is unclear however, how much of the overall score is influenced by the individual elements of push-ups, sit-ups, and the 2-mile run, and so each of these elements is discussed in detail below.

\section{Push-ups}

Three out of four studies conducted in the basic training environment found a relationship between a low level of push-ups performed in 2 minutes and injury risk in female trainees. The single study conducted in advanced training also found a relationship, despite the two conducted in active-duty female personnel not finding a significant relationship. The average number of repetitions conducted in the basic training environment by female personnel is substantially lower $(n=10.6-12.4$ repetitions $(26,28))$ than that in the female active duty population $(n=37$ repetitions $(1,34)$ ), which may explain this finding. Push-up performance may also be a proxy measure for general fitness (63), and exposure to physical training within the military may be adequate to increase fitness such that it is no longer a risk factor for injury. Furthermore, it may be that tasks performed in the military context are not overly reliant on upper limb endurance (27), and that perhaps measures of lower limb endurance may be more relevant, as lower limb endurance is more related to military tasks (64).

\section{Sit-ups}

Overall, there were variable results with respect to sit-up performance and injury risk for female soldiers, with just three of seven articles showing a relationship. Only one study in basic training, but both articles in active service personnel found a relationship between sit-up performance and injury risk. In line with push-up performance, sit-up performance may be an indicator of global fitness (63), with those who are more active being more proficient at this assessment. Sit-up performance, as a measure of trunk muscle endurance, has shown little correlation with common military tasks (64), with some questioning the appropriateness of the sit-up assessment within this environment (27).

\section{Strength, Speed, \& Power}

The inclusion of strength, speed, or power assessments in military contexts has increased, with both the vertical jump and grip strength assessments now being added to the Canadian military basic fitness test and various strength and power measurements now in the US Army Combat Fitness Test (ACFT) and 
Occupational Physical Assessment Test (OPAT) for combat arms soldiers specifically (65). Assessing strength in the military setting is complicated by the requirement for testing equipment, with few studies assessing this attribute. The results of the study by Kodesh et al (30), who found no relationship between $10 \mathrm{~m}$ sprint time, drop jump, or countermovement jump and injury risk, may be skewed by the environment, where soldiers were attending a combat fitness instructors' course. This may have led to those who were more athletically capable nominating themselves for this course and being included in the study. The single leg, triple hop distance did differentiate between female soldiers who were and were not injured (30), however, and so this warrants further investigation in future studies. Knapik et al. (36) found no association between any measure of upper or lower body strength or lower body power and injury risk in female soldiers during basic training.

\section{Flexibility}

Flexibility was only assessed as an injury risk factor in one study (36), which found no relationship between flexibility and injury risk in female soldiers. A previous review has questioned the relevance of flexibility, due to its lack of correlation to military specific tasks (64).

\section{Aerobic Fitness}

Aerobic fitness appears to be clearly related to injury risk in female soldiers, with all but one of the 11 included studies which reported on aerobic fitness showing significant associations between slow run times of any distance measured and injury risk, at all stages of a female soldier's career. The importance of aerobic fitness is further highlighted by its strong correlation with a high number of military specific tasks (64). The positive benefits of fitness appear to also negate the otherwise detrimental effects of a high BMI (27) or high percentage body fat (31). The study by Rappole et al (1), which did not find a significant association between injury risk and 2-mile run times, did not report run times of those who were and were not injured, making determination of the levels of fitness of each cohort difficult. The average run times in the overall combined cohort ranged from 17.87-18.31 mins, slower than the 17 minute cut off time used as a reference in the studies by both Grier et al., (24) and Roy (2). Additionally, it may be that serving soldiers in that study possessed adequate fitness to protect against injury and that a ceiling effect may have been reached (63), or that the method of injury data capture might have only captured more severe injuries for which a soldier sought care (66). It has been proposed that lower aerobic fitness, as opposed to sex/gender, is responsible for injury risk - in general, females have lower levels of aerobic fitness (67).

Some authors have advised against using a run time cut off for entry into military service prior to basic training, as there will be some who have slow run times who do not get injured and an injury does not necessarily mean an individual will not make it through basic training (25). However, categorizing individuals by run time may serve to highlight to physical training instructors those who would be best targeted by ability-based training $(68,69)$, to avoid an excessive intensity of training and concurrent increased injury risk. 


\section{Movement Assessments}

Only two included studies assessed movement, via the FMS (30), and a Y Balance assessment (32), as potential risk factors for injury in female soldiers. The lack of observed association between FMS scores and injury risk may be due to the training location in which the assessment was conducted. As the authors (30) discussed, those female soldiers assessed were attending a combat fitness instructors' course, and those who are more prone to injury may not have enrolled in this course. It should be noted that those who scored a zero in one or more movement assessments were more commonly injured during the course. Despite the composite score of the FMS as an injury prediction tool being more generally of questionable value (70), it has been found to be associated with injury risk within male military populations, albeit with a small magnitude of association (71). Pre-ranger soldiers who had reported either tobacco use or a previous musculoskeletal injury had lower FMS scores than those not reporting these (tobacco: $16.1 \pm 2.1$ vs $16.5 \pm 1.8$ points, $p=0.02$; injury: $16.0 \pm 2.2$ vs $16.6 \pm 1.8$ points, $p<0.01$ ) in the study by Davis et al., (53). Another finding in that study was that asymmetries identified in the FMS were not related to APFT scores, tobacco use, or self-rated fitness. Individual elements of the FMS may be more useful than the overall score, with those who scored a zero in one or more movement assessments more commonly injured during the combat fitness instructors course in the study by Kodesh et al (30), and the pain provocation tests reported to predict injury in male US Army rangers (72). The utility of the FMS, whether it be based on individual movements, pain clearing assessments or overall scores, remains unclear in female soldiers, due to both minimal research and low numbers of female participants.

Roy et al (32) found that those female soldiers with poorer single leg balance ability as measured by the $\mathrm{Y}$ balance composite score were more prone to injury than those with better balance scores. In a similar manner, deficits in the $Y$ balance assessment have been shown to be associated with patellofemoral pain in male military recruits $(73)$, and in a multitude of sporting contexts $(74,75)$. Its value in injury prediction for female soldiers warrants further investigation.

Overall, smoking, previous injury, history of no deployment, heavy occupational tasks while on deployment, low aerobic fitness and poor push-up performance appear to be associated with injury risk in female military personnel. Age, height, body mass, body fat, BMI and flexibility do not appear to be related, or appear to be inconsistently related, to injury risk. Minimal research has been performed on flexibility, current levels of activity and assessments of strength, power, speed, and movement in female personnel. Given that some known risk factors for injury in males, such as older age, BMI, body fat percentage, flexibility, and previous activity levels $(3,29,34,36)$, are not evident in female personnel, the reasons for these apparent sex differences warrant further investigation.

\section{Limitations}

Across the studies included in this review, there was wide variation in the definition of an injury, and this may have led to more minor injuries not being captured. The self-reporting of injuries is also problematic, as individuals may be reluctant to disclose them, fearing it may affect their entry to military service or their ongoing training. There were a variety of levels assessed for each risk factor, across the different 
studies, which made direct comparisons problematic. Entry to military service is also governed by fitness and medical standards, which may create a basement effect and exclude extremes of some measures (e.g., fitness, BMl, height, age) for many of the risk factors included. This may have led to a narrowing of the window for comparison for many measures and therefore may mean the findings of the review are not applicable to females outside of military service.

\section{Conclusion}

Smoking, a lack of deployment history, heavy occupational tasks on deployment, low aerobic fitness and poor push-up performance are associated with increases in injury risk in female soldiers. Being deployed on operations may be protective of injury for female personnel, due to ensuring personnel are sufficiently medically fit for deployment and providing opportunity for personnel to conduct self-paced physical training. Age, sit-up ability, BMI, bodyweight, body fat percentage and height appear to have minimal or inconsistent associations with injury risk in female soldiers, while there also appears to be minimal evidence at this stage for movement assessments such as the FMS being predictors of injury risk in female soldiers. Strategies to improve aerobic fitness and upper limb endurance, reduce smoking, and optimize rehabilitation of injuries and risk management of heavy occupational tasks need to be developed to reduce injury risks for female soldiers.

\section{Abbreviations}

ACFT: Army Combat Fitness Test, AIT: Advanced Individual Training, APFT: Army Physical Fitness Test, BMI: Body Mass Index, CASP: Critical Appraisal Skills Program, FMS: Functional Movement Screen, HR: Hazard Ratio, IDF: Israeli Defence Force, IRR: Incident Rate Ratio, OPAT: Occupational Physical Assessment Test, OR: Odds Ratio, PT: Physical Training, RR: Relative Risk, US: United States.

\section{Declarations}

\section{Ethics approval and consent to participate:}

Not applicable.

\section{Consent for publication:}

Not applicable

\section{Availability of data and material:}

Not applicable.

\section{Competing interests:}

The authors declare that they have no competing interests. 


\section{Funding:}

This project was supported by a grant from the Defence Health Foundation.

\section{Authors Contribution:}

$\mathrm{BS}, \mathrm{RO}$ and RP contributed to the study design, analysis and interpretation of results. BS \& EC were responsible for study selection, data extraction and critical appraisal. BS, EC, RO and RP contributed to the critical revision for publishing. All authors read and approved the final manuscript.

\section{Acknowledgements:}

The authors wish to thank the Defence Health Foundation for supporting this research project.

\section{References}

1. Rappole C, Chervak MC, Grier T, Anderson MK, Jones BH. Factors Associated with Lower Extremity Training-Related Injuries Among Enlisted Women in U.S. Army Operational Units. J Mil Veterans Health. 2018;26(1):18-28.

2. Roy TC, Songer T, Feifei $\mathrm{Y}$, LaPorte R, Grier T, Anderson M, et al. Physical Training Risk Factors for Musculoskeletal Injury in Female Soldiers. Mil Med. 2014;179(12):1432-8.

3. Bedno SA, Nelson DA, Kurina LM, Choi YS. Gender differences in the associations of body mass index, physical fitness and tobacco use with lower extremity musculoskeletal injuries among new US Army soldiers. Inj Prev. 2019;25(4):295-300.

4. Molloy JM, Pendergrass TL, Lee IE, Chervak MC, Hauret KG, Rhon DI. Musculoskeletal Injuries and United States Army Readiness Part I: Overview of Injuries and their Strategic Impact. Mil Med. 2020;185(9-10):e1461-e71.

5. Jones BH, Canham-Chervak M, Canada S, Mitchener TA, Moore S. Medical Surveillance of Injuries in the U.S. Military: Descriptive Epidemiology and Recommendations for Improvement. Am J Prev Med. 2010;38(1):S42-S60.

6. Hauret KG, Bedno S, Loringer K, Kao T-C, Mallon T, Jones BH. Epidemiology of Exercise- and SportsRelated Injuries in a Population of Young, Physically Active Adults: A Survey of Military Servicemembers. Am J Sports Med. 2015;43(11):2645.

7. Hauret KG, Taylor BJ, Clemmons NS, Block SR, Jones BH. Frequency and Causes of Nonbattle Injuries Air Evacuated from Operations Iraqi Freedom and Enduring Freedom, U.S. Army, 2001-2006. Am J Prev Med. 2010;38(1):S94-S107.

8. Butler NL. Injury prevention as a combat multiplier. Army War Coll Carlisle Barracks PA; 2008.

9. Bijur PE, Horodyski M, Egerton W, Kurzon M, Lifrak S, Friedman S. Comparison of injury during cadet basic training by gender. Arch Pediatr Adolesc Med. 1997;151(5):456-61. 
10. Hauret KG, Shippey DL, Knapik JJ. The physical training and rehabilitation program: duration of rehabilitation and final outcome of injuries in basic combat training. Mil Med. 2001;166(9):820-6.

11. Belmont Jr PJ, Goodman GP, Waterman B, DeZee K, Burks R, Owens BD. Disease and Nonbattle Injuries Sustained by a U.S. Army Brigade Combat Team During Operation Iraqi Freedom. Mil Med. 2010;175(7):469-76.

12. Le TD, Gurney JM, Nnamani NS, Gross KR, Chung KK, Stockinger ZT, et al. A 12-Year Analysis of Nonbattle Injury Among US Service Members Deployed to Iraq and Afghanistan. JAMA Surg. 2018;153(9):800-7.

13. Kovčan B, Vodičar J, Šimenko J, Videmšek M, Pori P, Vedran H, et al. Retrospective and Crosssectional Analysis of Physical Training-Related Musculoskeletal Injuries in Slovenian Armed Forces. Mil Med. 2019;184(1/2):e195-e9.

14. Cosio-Lima L, Brown K, Reynolds KL, Gregg R, Perry Jr RA. Injury and Illness Incidence in a Sergeants Major Academy Class. Mil Med. 2013;178(7):735-41.

15. Orr RM, Pope R. Gender differences in load carriage injuries of Australian army soldiers. BMC Musculoskelet Disord. 2016;17(1):488.

16. Finestone A, Milgrom C, Evans R, Yanovich RAN, Constantini N, Moran DS. Overuse Injuries in Female Infantry Recruits during Low-Intensity Basic Training. Med Sci Sports Exerc. 2008;40:S630-S5.

17. Almeida SA, Trone DW, Leone DM, Shaffer RA, Patheal SL, Long K. Gender differences in musculoskeletal injury rates: a function of symptom reporting? Med Sci Sports Exerc. 1999;31(12):1807-12.

18. O'Leary TJ, Saunders SC, McGuire SJ, Venables MC, Izard RM. Sex Differences in Training Loads during British Army Basic Training. Med Sci Sports Exerc. 2018;50(12):2565-74.

19. Moher D, Liberati A, Tetzlaff J, Altman DG. Preferred reporting items for systematic reviews and meta-analyses: the PRISMA statement. BMJ. 2009;339:b2535.

20. Critical Appraisal Skills Program. CASP Cohort Studies Checklist 2018 [Available from: https://caspuk.net/wp-content/uploads/2018/01/CASP-Cohort-Study-Checklist_2018.pdf.

21. Downes MJ, Brennan ML, Williams HC, Dean RS. Development of a critical appraisal tool to assess the quality of cross-sectional studies (AXIS). BMJ open. 2016;6(12):e011458-e.

22. Altarac M, Gardner JW, Popovich RM, Potter R, Knapik JJ, Jones BH. Cigarette smoking and exerciserelated injuries among young men and women. Am J Prev Med. 2000;18(3 Suppl):96-102.

23. Grier TL, Knapik JJ, Canada S, Canham-Chervak M, Jones BH. Risk factors associated with selfreported training-related injury before arrival at the US army ordnance school. Public health. 2010;124(7):417-23.

24. Grier TL, Morrison S, Knapik JJ, Canham-Chervak M, Jones BH. Risk factors for injuries in the U.S. Army Ordnance School. Mil Med. 2011;176(11):1292-9.

25. Heller R, Stammers H. Running to breaking point? The relationship between 1.5-mile run time and injury risk in female recruits during British Army basic training. J R Army Med Corps. 2019. 
26. Jones $\mathrm{BH}$, Bovee MW. Intrinsic risk factors for exercise-related injuries among male and female army trainees. Am J Sports Med. 1993;21(5):705.

27. Jones BH, Hauret KG, Dye SK, Hauschild VD, Rossi SP, Richardson MD, et al. Impact of physical fitness and body composition on injury risk among active young adults: A study of Army trainees. $J$ Sci Med Sport. 2017;20 Suppl 4:S17-s22.

28. Knapik JJ, Canham-Chervak M, Hoedebecke E, Hewitson WC, Hauret K, Held C, et al. The fitness training unit in U.S. Army basic combat training: physical fitness, training outcomes, and injuries. Mil Med. 2001;166(4):356-61.

29. Knapik JJ, Swedler DI, Grier TL, Hauret KG, Bullock SH, Williams KW, et al. Injury reduction effectiveness of selecting running shoes based on plantar shape. J Strength Cond Res. 2009;23(3):685-97.

30. Kodesh E, Shargal E, Kislev-Cohen R, Funk S, Dorfman L, Samuelly G, et al. Examination of the Effectiveness of Predictors for Musculoskeletal Injuries in Female Soldiers. J Sports Sci Med. 2015;14(3):515-21.

31. Krauss MR, Garvin NU, Boivin MR, Cowan DN. Excess Stress Fractures, Musculoskeletal Injuries, and Health Care Utilization Among Unfit and Overweight Female Army Trainees. Am J Sports Med. 2017;45(2):311-6.

32. Roy TC, Piva SR, Christiansen BC, Lesher JD, Doyle PM, Waring RM, et al. Heavy Loads and Lifting are Risk Factors for Musculoskeletal Injuries in Deployed Female Soldiers. Mil Med. 2016;181(11):e1476-e83.

33. Roy TC, Ritland BM, Sharp MA. A description of injuries in men and women while serving in Afghanistan. Mil Med. 2015;180(2):126-31.

34. Anderson MK, Grier T, Dada EO, Canham-Chervak M, Jones BH. The Role of Gender and Physical Performance on Injuries: An Army Study. Am J Prev Med. 2017;52(5):e131-e8.

35. Henderson NE, Knapik JJ, Shaffer SW, McKenzie TH, Schneider GM. Injuries and injury risk factors among men and women in U.S. Army Combat Medic Advanced individual training. Mil Med. 2000;165(9):647-52.

36. Knapik JJ, Sharp MA, Canham-Chervak M, Hauret K, Patton JF, Jones BH. Risk factors for trainingrelated injuries among men and women in basic combat training. Med Sci Sports Exerc. 2001;33(6):946-54.

37. Knapik JJ, Sharp MA, Montain SJ. Association between stress fracture incidence and predicted body fat in United States Army Basic Combat Training recruits. BMC Musculoskelet Disord. 2018;19(1):161.

38. Roy TC, Piva SR, Christiansen BC, Lesher JD, Doyle PM, Waring RM, et al. Description of musculoskeletal injuries occurring in female soldiers deployed to Afghanistan. Mil Med. 2015;180(3):269-75.

39. Tomes CD, Sawyer S, Orr R, Schram B. Ability of fitness testing to predict injury risk during initial tactical training: a systematic review and meta-analysis. Inj Prev. 2020;26(1):67-81. 
40. Knapik J, Ang P, Reynolds K, Jones B. Physical Fitness, Age, and Injury Incidence in Infantry Soldiers. J Occup Med. 1993;35(6):598-603.

41. Knapik JJ, Canham-Chervak M, Hauret K, Hoedebecke E, Laurin MJ, Cuthie J. Discharges during U.S. Army basic training: injury rates and risk factors. Mil Med. 2001;166(7):641-7.

42. Jones BH, Cowan DN, Tomlinson JP, Robinson JR, Polly DW, Frykman PN. Epidemiology of Injuries Associated With Physical Training Among Young Men in the Army. Med Sci Sports Exerc. 1993;25(2):197-203.

43. Schram B, Orr R, Pope R, Canetti E, Knapik J. Risk factors for development of lower limb osteoarthritis in physically demanding occupations: A narrative umbrella review. J Occup Health. 2020;62(1).

44. Kelly EW, Jonson SR, Cohen ME, Shaffer R. Stress fractures of the pelvis in female navy recruits: an analysis of possible mechanisms of injury. Mil Med. 2000;165(2):142-6.

45. Knapik JJ, Sharp MA, Steelman RA. Secular Trends in the Physical Fitness of United States Army Recruits on Entry to Service, 1975-2013. J Strength Cond Res. 2017;31(7):2030-52.

46. Pope RP, Herbert R, Kirwan JD, Graham BJ. Predicting attrition in basic military training. Mil Med. 1999;164(10):710-4.

47. Schram B, Pope RR, Orr RM. Injuries in Australian Army full-time and part-time personnel undertaking basic training. BMC Musculoskelet Disord. 2019;20(1).

48. Kucera KL, Marshall SW, Wolf SH, Padua DA, Cameron KL, Beutler Al. Association of Injury History and Incident Injury in Cadet Basic Military Training. Med Sci Sports Exerc. 2016;48(6):1053-61.

49. Hill OT, Bulathsinhala L, Scofield DE, Haley TF, Bernasek TL. Risk factors for soft tissue knee injuries in active duty U.S. Army soldiers, 2000-2005. Mil Med. 2013;178(6):676-82.

50. Orr RM, Coyle J, Johnston V, Pope R. Self-reported load carriage injuries of military soldiers. Int J Inj Contr Saf Promot. 2017;24:189-97.

51. Murphy DF, Connolly DAJ, Beynnon BD. Risk factors for lower extremity injury: a review of the literature. Br J Sports Med. 2003;37(1):13-29.

52. Orr RM, Schram B, Pope RR. Sports Injuries in the Australian Regular Army. Safety. 2020;6(23).

53. Davis JD, Orr R, Knapik JJ, Harris D. Functional Movement Screen (FMS $\left.{ }^{\mathrm{TM}}\right)$ Scores and Demographics of US Army Pre-Ranger Candidates. Mil Med. 2020;185(5-6):e788-e94.

54. Kelly KR, Jameson JT. Preparing for Combat Readiness for the Fight: Physical Performance Profile of Female U.S. Marines. J Strength Cond Res. 2016;30(3):595-604.

55. Goodall R, Pope R, Coyle J, Neumayer R. Balance and agility training does not always decrease lower limb injury risks: a cluster-randomised controlled trial. Inj J Inj Contr Saf Promot. 2013;20(3):271-81.

56. Anderson MK, Grier T, Canham-Chervak M, Bushman TT, Jones BH. Physical training, smoking, and injury during deployment: a comparison of men and women in the US Army. US Army Med Dep J. 2015:42-8. 
57. Knapik JJ, Scott SJ, Sharp MA, Hauret KG, Darakjy S, Rieger WR, et al. The basis for prescribed ability group run speeds and distances in U.S. Army basic combat training. Mil Med. 2006;171(7):669-77.

58. Lauder TD, Baker SP, Smith GS, Lincoln AE. Sports and physical training injury hospitalizations in the army. Am J Prev Med. 2000;18(3 Suppl):118-28.

59. Roy TC, Knapik JJ, Ritland BM, Murphy N, Sharp MA. Risk factors for musculoskeletal injuries for soldiers deployed to Afghanistan. Aviat Space Environ Med. 2012;83(11):1060-6.

60. Coltman CE, Steele JR, Spratford WA, Molloy RH. Are female soldiers satisfied with the fit and function of body armour? Appl Ergon. 2020;89:103197-.

61. Orr RM, Pope R, Coyle J, Johnston V. Occupational loads carried by Australian soldiers on military operations. J Health Saf Environ. 2015;31(1):451-67.

62. Dulla J, Baran K, Pope R, Orr R. Duty loads carried by the LA sheriff's department officers. J Sci Med Sport. 2017;20:S5-S6.

63. Tomes C, Schram B, Pope R, Orr R. What is the impact of fitness on injury risk during police academy training? A retrospective cohort study. BMC Sports Sci Med Rehabilitation. 2020;12(1):39-.

64. Hauschild VD, DeGroot DW, Hall SM, Grier TL, Deaver KD, Hauret KG, et al. Fitness tests and occupational tasks of military interest: a systematic review of correlations. J Occup Environ. 2017;74(2):144-53.

65. Foulis SA, Sharp MA, Redmond JE, Frykman PN, Warr BJ, Gebhardt DL, et al. U.S. Army Physical Demands Study: Development of the Occupational Physical Assessment Test for Combat Arms soldiers. J Sci Med Sport. 2017;20:S74-S8.

66. Pope R, Orr R. Incidence rates for work health and safety incidents and injuries in Australian Army Reserve vs full time soldiers, and a comparison of reporting systems. J Mil Veterans Health. 2017;25(2):16-25.

67. Bell NS, Mangione TW, Hemenway D, Amoroso PJ, Jones BH. High injury rates among female army trainees: a function of gender? Am J Prev Med. 2000;18(3 Suppl):141-6.

68. Orr RM, Ford K, Stierli M. Implementation of an ability-based training program in police force recruits. J Strength Cond Res. 2016;30(10):2781-7.

69. Lockie R, Dulla J, Orr R, Dawes J. Importance of Ability-Based Training for Law Enforcement Recruits. Strength Cond J. 2020;Publish Ahead of Print.

70. Bock C, Orr RM. Use of the functional movement screen in a tactical population: A review. J Mil Veterans Health. 2015;23(2):33-42.

71. Moran RW, Schneiders AG, Mason J, Sullivan SJ. Do Functional Movement Screen (FMS) composite scores predict subsequent injury? A systematic review with meta-analysis. $\mathrm{Br} \mathrm{J}$ Sports Med. 2017; 51(23):1661-9.

72. Teyhen DS, Shaffer SW, Butler RJ, Goffar SL, Kiesel KB, Rhon DI, et al. What Risk Factors Are Associated With Musculoskeletal Injury in US Army Rangers? A Prospective Prognostic Study. Clin Orthop Relat Res. 2015;473(9):2948-58. 
73. Nakagawa TH, dos Santos AF, Lessi GC, Petersen RS, Scattone Silva R. Y-Balance Test Asymmetry and Frontal Plane Knee Projection Angle During Single-leg squat as Predictors of Patellofemoral Pain in Male Military Recruits. Phys Ther Sport. 2020;44:121-7.

74. Smith CA, Chimera NJ, Warren M. Association of Y Balance Test Reach Asymmetry and Injury in Division I Athletes. Med Sci Sports Exerc. 2015;47(1):136-41.

75. Hartley EM, Hoch MC, Boling MC. Y-balance test performance and BMI are associated with ankle sprain injury in collegiate male athletes. J Sci Med Sport. 2018;21(7):676-80.

\section{Table}

Due to technical limitations, table 2 docx is only available as a download in the Supplemental Files section.

\section{Figures}




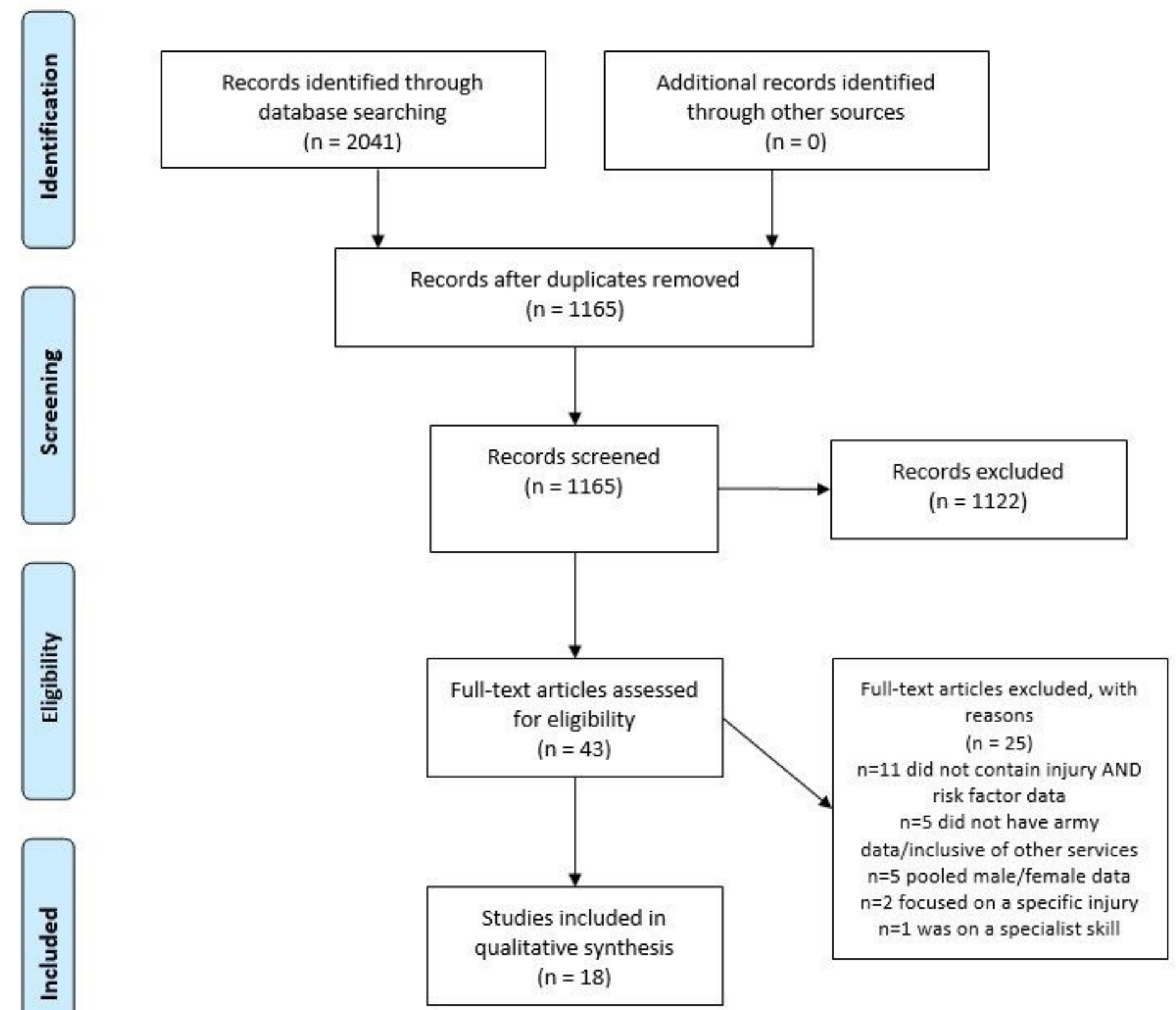

\section{Figure 1}

PRISMA FLOW CHART (19) SHOWING THE SCREENING AND SELECTION PROCESS

\section{Supplementary Files}

This is a list of supplementary files associated with this preprint. Click to download.

- Table2.docx 